\title{
Hubungan Dehidrasi Terhadap Memori Segera/Atensi
}

\author{
${ }^{1}$ Mochamad Bahrudin, ${ }^{2}$ Annisa Bunga Nafara \\ ${ }^{1}$ Staf pengajar bagian Ilmu Penyakit Syaraf Fakultas Kedokteran Universitas \\ Muhammadiyah Malang J1. Bendungan Sutami 188A Malang Telp 0341_552442, Fax \\ 0341_582060 \\ ${ }^{2}$ Mahasiswa Fakultas Kedokteran Universitas Muhammadiyah Malang \\ Email : mochbahrudin1012@gmail.com \\ Diterima : 23 April 2019. Perbaikan : 14 Mei 2019. Diterbitkan : 29 Juni 2019. \\ DOI : https://doi.org/10.22219/sm.Vol15.SMUMM1.8487
}

\begin{abstract}
ABSTRAK
Dehidrasi adalah kondisi kekurangan atau kehilangan cairan dari seluruh kompartemen tubuh. Kekurangan cairan minimal 1\% dapat mempengaruhi fungsi kognitif otak termasuk penurunan kemampuan daya ingat jangka pendek. Penelitian ini untuk mengetahui hubungan dehidrasi terhadap memori segera/atensi Rancangan penelitian dengan True Experimental, Pre test and post Test with Control Group Design dengan dua kelompok, kontrol dan kelompok perlakuan (induksi dehidrasi ringan dengan treadmil 5,6 km/jam selama 40 menit, kemudian istirahat 20 menit). Instrumen yang digunakan adalah WAIS Digit Span Backward. Analisa data menggunakan Uji Chi-Square, Mann-Whitney Test, Nonparametric Correlations Spearman's dan uji Regression. Dari penelitian ini didapatkan hasil prosentase penurunan memori segera/atensi pada kelompok tidak dehidrasi 16,1\%, kelompok dehidrasi.adalah 30,6\% dan Pada Uji Chi-Square signifikansi P=0,02. uji NP Nonparametric Correlations Spearman's signifikansi $\mathrm{P}=0.004$ artinya ada korelasi antara beratnya dehidrasi dengan penurunan memori segera/Atensi dan pada uji regressi didapat korelasi negatif artinya semakin besar nilai dehidrasi maka semakin berat derajat penurunan memori segera/Atensi. Dari penelitian ini didapatkan hubungan dehidrasi terhadap memori segera/atensi dengan korelasi negatif.
\end{abstract}

Kata kunci : Prediksi, Hasil Belajar, IPK, UKMPPD. 


\section{ABSTRACT}

Debydration is a condition of lack or loss of fluid from all body compartments. A minimum of $1 \%$ fluid deficiency can affect brain cognitive function including a decrease in short-term memory abilities. This research is to find out the relationship of immediate / attention debydration to memory The study design was True Experimental, Pre test and post Test with Control Group Design with two groups, control and treatment group (induction of mild dehydration with treadmill $5.6 \mathrm{~km} / \mathrm{h}$ for 40 minutes, then rest 20 minutes). The instrument used is WAIS Digit Span Backward. Data analysis using the Chi-Square Test, Mann-Whitney Test, Nonparametric Correlations Spear's and Regression tests. From this study, the percentage of immediate / attention reduction in the non-dehydrated group was $16.1 \%$, the debydration group was $30.6 \%$ and in the ChiSquare Test the significance was $P=0.02$. Nonparametric Correlations Spearmanship NP test significance of $P=0.004$ means that there is a correlation between the severity of debydration and the immediate decline in memory / Attention and in the regression test negative correlation means the greater the value of dehydration, the more severe the degree of memory decline / Attention. From this study, the association of immediate debydration / attention with negative correlation was found.

Keywords : Dehydration,; immediate memory; Attention.

\section{PENDAHULUAN}

Memori adalah kemampuan untuk menyandikan, menyimpan, menyaji, mengontrol, dan kemudian mengingat kembali informasi dan pengalaman masa lalu tersebut dalam otak manusia. Memori adalah total dari apa yang kita ingat, yang membuat kita mampu mempelajari dan beradaptasi dari pengalaman masa lalu (Luke Mastin, 2010). Memori Segera adalah pemanggilan segera, merupakan pemanggilan setelah rentang waktu beberapa detik, seperti pada pengulangan deretan angka dan memori segera ini sama kemeriksaanya dengan atensi (Bahrudin, 2011). Memori segera sangat penting diperiksa karena merupakan tahapan awal sebelum suatu ingatan berubah menjadi memori jangka panjang (Johnson, 2008).

Dehidrasi adalah kehilangan cairan dari keseluruhan kompartemen tubuh. Dehidrasi disebabkan karena kebutuhan cairan lebih banyak dari asupan yang mengakibatkan volume cairan dalam darah berkurang. (Guyton, 2012). Seseorang dikatakan dehidrasi ringan (cairan tubuh berkurang 1-3\%) bila mengalami gejala-gejala seperti keringnya mukosa, turgor kulit menurun, lesu, gelisah, mata cekung urin keruh, menurunnya tekanan darah, hingga gejala gangguan fisik, psikologis, suasana hati (mood), dan gangguan fungsi kognitif (David Benton, 2011, Kemenkes, 2011).

Penurunan memori biasanya terjada pada usia lanjut. Namun kini, usia muda banyak juga yang mengalami keluhan penurunan memori segera, hal ini sesuai dengan penelitian Achmad Iwan Tantomi, 2013 yang berjudul “Tren Fenomena 'PisiDi’ (Pikun Usia Dini) sebagai Dugaan Awal Gejala Demensia di Kota Malang”. Usia muda terutama mahasiswa merupakan usia resiko tinggi kejadian dehidrasi, sebagai contoh di UGM didapatkan sebanyak 60,9\% mahasiswa mengalami involuntary debydration (Penggalih, 2013). Penelitian Gustam, 2012 yang yang meneliti tentang Faktor Risiko Dehidrasi pada Remaja dan Dewasa membuktikan status dehidrasi pada dewasa dan remaja adalah 48,1\% dan 44,5\%. Penelitian C. Ferreira Pego,2015 menyebutkan hanya 40\% pria dan 60\% wanita yang memenuhi asupan cairannya sesuai dengan EFSA (European Food Safety Agency), 39,3\% 
di antaranya adalah kalangan usia 18-29 tahun. Menurut Armstrong, 2010 sebagian besar orang dewasa mengkonsumsi cairan rata-rata kurang dari 2,1L perhari. Penelitian lain menunjukan rentang usia 15-24 tahun tidak mengkonsumsi air yang cukup (rata-rata 1,5 liter perhari untuk laki-laki, dan 1,6 liter perhari untuk perempuan) (Penggalih, 2013).

Beberapa penelitian membuktikan bahwa dehidrasi memberikan pengaruh pada fungsi kognitif, peforma, dan mood (suasana hati), dangan uji Cognitive Performance and self report questionnaires. (Harris R Lieberman, 2012). Penelitian Lawrence E. Armstrong, 2012, mengunakan sampel 25 orang perempuan dengan usia rata-rata 23 tahun di induksi dehidrasi dengan aktivitas fisik dan tablet diuretik, menunjukan adanya penurunan skor pada uji cognitive test battery (computerized cognitive test software, version 1.2.4). Hal ini membuktikan bahwa dehidrasi dapat mempengaruhi fungsi fisiologis otak.

Penelitian ini menggunakan sampel mahasiswa kedokteran FK-UMM semester akhir karena pada semester tersebut kegiatan dan aktifitas sangat banyak sehingga memerlukan energi yang banyak dan kondisi kesehatan yang optimal. Mahasiswa di tuntut untuk mencapai prestasi akademik yang baik. Kondisi fisik yang prima dapat dipenuhi dengan kondisi hidrasi tubuh yang baik (Penggalih, 2013). Jadwal kuliah yang padat dan banyaknya kegiatan non-akademik yang dilakukan mahasiswa mengakibatkan turunnya konsumsi cukup cairan yang dapat meningkatkan risiko dehidrasi pada mahasiswa.

Berdasarkan uraian diatas peneliti ingin membuktikan apakah ada hubungan dehidrasi yang ringan (cairan tubuh berkurang 1-3\%) dengan penurunan memori segera atau atensi.

\section{METODE}

Jenis dan Rancangan penelitian ini menggunakan true eksperimental, menggunakan pre test and post test with control group.

Penelitian ini dilakukan di Sport Center UB, Jalan Terusan Cikampek No. 1, Malang, selama 3 bulan pada bulan Agustus-Desember 2017.

Populasi Penelitian adalah mahasiswa laki-laki Fakultas Kedokteran Universitas Muhammadiyah Malang.

Sampel Penelitian adalah mahasiswa laki-laki Fakultas Kedokteran Universitas Muhammadiyah Malang tahun ketiga yang memenuhi kriteria inklusi dengan besar sampel menggunakan rumus Slovin :

$$
\mathrm{n}=\frac{\mathrm{N}}{1+\mathrm{Ne}^{2}}
$$

$\mathrm{n}=$ ukuran sampel 
$\mathrm{N}=$ ukuran populasi

$\mathrm{d}=$ Presisi yang di inginkan (misal 10\%)

$$
\mathrm{n}=\frac{158}{1+158 \times 0,1^{2}}=61,2(62 \text { orang })
$$

Sampel di ambil dengan metode simple random pada mahasiswa laki-laki FK-UMM angkatan 2013, 49 mahasiswa dan angkatan 201446 mahasiswa. Sampel akan diberikan kuisioner yang berisi informasi tentang status hidrasi, riwayat penyakit responden (meliputi penyakit neurologis, ginjal, riwayat penyakit sekarang, kondisi psikologis), indeks masa tubuh, faktor aktifitas sehari-hari (kebiasaan olahraga, pola makan, nutrisi, konsumsi kafein, pola tidur), kondisi fisik dan konsumsi alkohol, sehingga dari kuesioner ini akan di dapat subjek yang memenuhi kriteria inklusi. Setelah dilakukan penentuan sampel sesuai karakteristik yang dinginkan, Subjek diberitahu syarat-syarat dan persiapan perlakuan induksi dehidrasi (tidur yang cukup di malam harinya, tidak mengkonsumsi alkohol dan kafein 12 jam sebelumnya, mengkonsumsi $240 \mathrm{ml}$ air sebelum tidur dan pagi harinya bukan minuman elektrolit, makan yang cukup saat makan malam dan sarapan). Subjek melakukan pre test terlebih dahulu dengan WAIS Digit span. Kemudian kelompok perlakuan di ukur Berat badannya, lalu melakukan aktifitas fisik treadmil secara bergantian sesuai dengan prosedur di atas selama 40 menit, dan kelompok kontrol tidak melakukan treadmill. Subjek kelompok perlakuan istirahat selama 20 menit tanpa diberi air. Subjek di ukur kembali berat badannya, kemudian dilakukan uji daya ingat jangka pendek. Sebagai post test dengan WAIS Digit span. Hasil post test dan pretest pada kedua kelompok tersebut di analisa. Analisa data menggunakan Uji Chi-Square, Mann-Whitney Test, Nonparametric Correlations Spearman's dan uji Regression.

\section{HASIL DAN DISKUSI}

Penelitian ini dilakukan pada bulan Agustus sampai Desember 2017, memakai metode penelitian eksperimental dengan desain the pre test and post test with control group. Sampel penelitian 62 subjek yang dibagi 2 kelompok, masing - masing 31 subyek kontrol dan perlakuan. Masing-masing kelompok dilakukan uji memori jangka pendek / atensi pretest dan posttest WAIS (Wechsler Adult Intelligence Scale) digit span backward, untuk mengetahui pengaruh dehidrasi terhadap memori segera/atensi.

Dari tabel 1.1 terlihat pada kelompok kontrol terjadi peningkatan skor WAIS (Wechsler Adult Intelligence Scale) digit span backward dari 3,806 menjadi 4,097, sedang pada kelompok kontrol (dehidrasi) terjadi penurunan dari 3,548 menjadi 3,064 dan hasil T-test Paired pada tabel 1.2 signifikan $(\mathrm{P}=0,000)$.

Dari tabel 1.3 tampak pada kelompok kontrol (tidak dehidrasi) memori /atensi menurun 16,1\% dan normal 33,9\% sedang pada kelompok perlakuan (dehidrasi) memori /atensi menurun 
30,6\% dan normal 19,4\% dengan nilai P signifikan yang artinya ada hubungan antara dehidrasi dengan penurunan memori segera/atensi.

Tabel 1.1. Data Primer Hasil Penelitian

Kelompok Kontrol / Non Dehidrasi

\begin{tabular}{|c|c|c|c|c|}
\hline $\begin{array}{l}\text { Nomor } \\
\text { sampel }\end{array}$ & $\begin{array}{c}\text { Skor Pretest WAIS } \\
\text { Digitspan }\end{array}$ & $\begin{array}{c}\text { Skor Posttest WAIS } \\
\text { Digitspan }\end{array}$ & $\begin{array}{l}\text { selisih } \\
\text { skor }\end{array}$ & $\begin{array}{c}\text { \% kehilangan } \\
\text { cairan }\end{array}$ \\
\hline 1 & 4 & 4 & 0 & 0 \\
\hline 2 & 5 & 5 & 0 & 0 \\
\hline 3 & 4 & 4 & 0 & 0 \\
\hline 4 & 3 & 5 & 2 & 0 \\
\hline 5 & 4 & 4 & 0 & 0 \\
\hline 6 & 4 & 5 & 1 & 0 \\
\hline 7 & 4 & 5 & 1 & 0 \\
\hline 8 & 4 & 6 & 2 & 0 \\
\hline 9 & 3 & 2 & -1 & 0 \\
\hline 10 & 3 & 3 & 0 & 0 \\
\hline 11 & 6 & 6 & 0 & 0 \\
\hline 12 & 3 & 4 & 1 & 0 \\
\hline 13 & 5 & 5 & 0 & 0 \\
\hline 14 & 4 & 3 & -1 & 0 \\
\hline 15 & 4 & 3 & -1 & 0 \\
\hline 16 & 3 & 3 & 0 & 0 \\
\hline 17 & 3 & 4 & 1 & 0 \\
\hline 18 & 4 & 5 & 1 & 0 \\
\hline 19 & 4 & 4 & 0 & 0 \\
\hline 20 & 4 & 4 & 0 & 0 \\
\hline 21 & 2 & 3 & 1 & 0 \\
\hline 22 & 3 & 3 & 0 & 0 \\
\hline 23 & 7 & 7 & 0 & 0 \\
\hline 24 & 6 & 6 & 0 & 0 \\
\hline 25 & 3 & 4 & 1 & 0 \\
\hline 26 & 4 & 4 & 0 & 0 \\
\hline 27 & 3 & 3 & 0 & 0 \\
\hline 28 & 3 & 3 & 0 & 0 \\
\hline 29 & 4 & 4 & 0 & 0 \\
\hline 30 & 3 & 4 & 1 & 0 \\
\hline
\end{tabular}




\begin{tabular}{ccccc}
\hline 31 & 2 & 2 & 0 & 0 \\
\hline Rata-rata & 3,806 & 4,097 & 0 \\
\hline
\end{tabular}

Tabel 1.2 Hasil rata-rata skor pre test dan post test kelompok perlakuan dan kontrol

Kelompok kontrol

\begin{tabular}{cccc}
\hline & Rata skor & Jumlah sampel & $\mathrm{p}$ \\
\hline Pre test & 3.81 & 31 & 0,000 \\
Post test & 4.01 & 31 & \\
\hline
\end{tabular}

Kelompok perlakuan

\begin{tabular}{llll}
\hline & Rata skor & Jumlah sampel & $\mathrm{p}$ \\
\hline Pre test & 3.55 & 31 & 0,000 \\
Post test & 3.06 & 31 & \\
\hline
\end{tabular}

Data primer diolah

Tabel 1.3. Tabulasi silang kelompok kontrol dan perlakuan

\begin{tabular}{|c|c|c|c|c|}
\hline \multirow[t]{2}{*}{ Dehidrasi } & \multicolumn{2}{|c|}{ Memori segera/Atensi } & \multirow[t]{2}{*}{ Total } & \multirow[t]{2}{*}{$\mathrm{P}$} \\
\hline & Menurun & Normal & & \\
\hline Non dehidrasi & $10(16,1 \%)$ & $21(33,9 \%)$ & 31 & 0,02 \\
\hline \multirow[t]{2}{*}{ Dehidrasi } & $19(30,6 \%)$ & $12(19,4 \%)$ & 31 & \\
\hline & $29(46,8 \%)$ & $33(53,2 \%)$ & $62(100 \%)$ & \\
\hline
\end{tabular}

Data primer diolah

Tabel 1.4. Uji Normalitas

\begin{tabular}{cccc}
\hline & $\begin{array}{c}\text { Kolmogorov- } \\
\text { Smirnov }\end{array}$ & Shapiro-wilk & \\
\cline { 2 - 3 } & statistic & statistic & \\
\hline Penurunan memori segera / Atensi & 0,0251 & 0,886 & 0,00 \\
\hline
\end{tabular}

Tabel 1.4. Menunjukkan uji normalitas nilai $\mathrm{P}=0,00$ artinya distribusi data tidak normal maka untuk uji korelasi kita gunakan NPar Tests Mann-Whitney Test 
Tabel 1.5. Uji NPar Tests Mann-Whitney Test

\begin{tabular}{clccc}
\hline Kelompok & & N & Mean Rank & P \\
\hline Penurunan memori segera/Atensi & Kontrol & 31 & 38.81 & 0.001 \\
& Perlakuan & 31 & 24.19 & \\
& Total & 62 & & \\
\hline
\end{tabular}

Tabel 1.5 uji NPar Tests Mann-Whitney Test didapat nilai $\mathrm{P}=0.001$ artinya ada hubungan antara dehidrasi dengan penurunan memori segera/Atensi.

Untuk mengetahui korelasi antara antara beratnya dehidrasi dan penurunan memori segera/atensi kita gunakan uji Nonparametric Correlations karena distribusi data tidak normal karena pada uji normalitas $\mathrm{P}<0.05$, maka kita gunakan uji Nonparametric Correlations Spearman's

Tabel 1.6 Nonparametric Correlations Spearman's

\begin{tabular}{lccc}
\hline & $\begin{array}{c}\text { Penurunan memori } \\
\text { segera / Atensi }\end{array}$ & & \\
& & & \\
& & & \\
\hline Penurunan memori segera / Atensi & 1.000 & $-0,365$ & 0,004 \\
Dehidrasi & $-0,365$ & 1,000 & \\
\end{tabular}

Pada tabel 1.6 uji NP Nonparametric Correlations Spearman's didapat nilai $\mathrm{P}=0.004$ artinya ada korelasi antara beratnya dehidrasi dengan penurunan memori segera/Atensi.

Untuk memprediksikan penurunan memori segera/atensi dan melihat berapa kontribusi dehidrasi pada kejadian penurunan memori segera/atensi kita gunakan uji Regression.

Untuk melihat berapa kontribusi dehidrasi pada kejadian penurunan atensi (r square x 100). Untuk memprediksikan penurunan atensi $(y=a+b x)$.

Dari gambar 1.1 dapat disimpulkan bahwa korelasi antara beratnya dehidrasi dengan penurunan memori segera/atensi adalah korelasi negatif artinya semakin besar nilai dehidrasi maka semakin berat derajat penurunan memori segera/Atensi. 


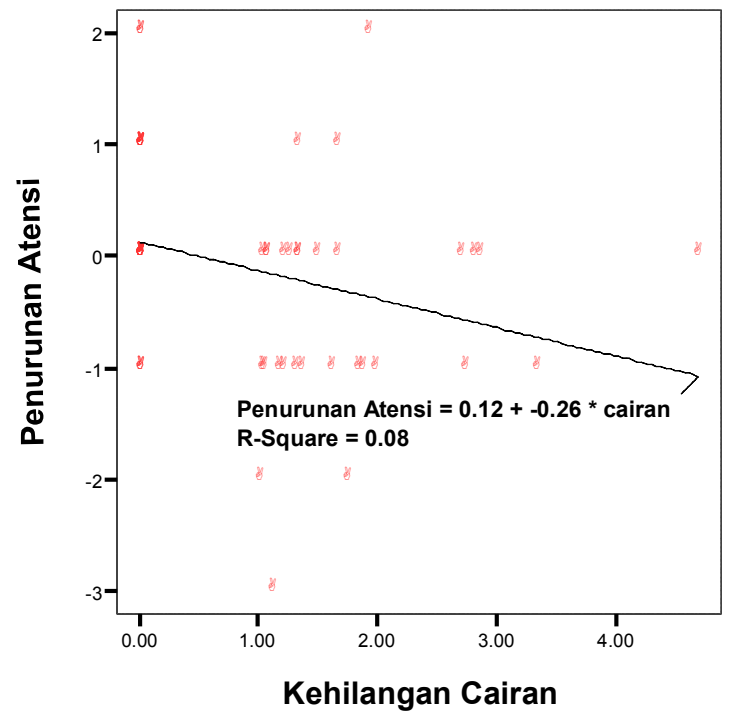

Linear Regression

Gambar 1.1. Korelasi antara derajat dehidrasi dan memori jangka pendek / atensi

Pembahasan

Penelitian ini menggunakan 62 sampel dibagi menjadi 2 kelompok yaitu kelompok kontrol (tidak dehidrasi) dan perlakuan (dehidrasi). Faktor-faktor yang mempengaruhi memori dan atensi yaitu jenis kelamin, usia, nutrisi, penyakit sistem saraf pusat, gangguan psikologis, pola tidur, dan kelainan kongenital sudah dikeluarkan dengan menggunakan kuisner sehingga diharapkan hasil yang lebih baik. Faktor-faktor yang mempengaruhi status hidrasi seperti BMI, kebiasaan olahraga, riwayat penyakit ginjal dan sehat jasmani rohani diseimbangkan antara kontrol dan perlakuan, kemudian satu hari sebelum perlakuan juga di adakan briefing oleh peneliti mengenai persiapan perlakuan untuk mendapatkan sampel yang homogenitas.

Pada penelitian ini dehidrasi ringan diinduksi dengan aktifitas fisik yaitu treadmil selama 40 menit dengan kecepatan 5,6 km/jam, grade $5 \%$, dengan suhu ruangan $27,6 \pm 0,8^{\circ} \mathrm{C}$ dan dapatkan rata kehilangan cairan $1,733 \%$ (tabel 1.1). Kehilangan 1\% cairan dari dalam tubuh merupakan nilai minimal yang dapat mempengaruhi fungsi otak, hal ini didukung penelitan Ganio (2011), menggunakan 26 pria berusia 20 tahun bahwa dehidrasi ringan yang diinduksi oleh aktifitas fisik (treadmil 40 menit dengan kecepatan 5,6 km/jam) dapat mengganggu mood dan fungsi kognitif yang meliputi daya ingat jangka pendek yang diuji menggunakan Computer Based Test (Ganio, et al. 2011)

Berdasarkan hasil penelitian tabel 1.2 didapatkan bahwa kelompok perlakuan (dehidrasi) mengalami penurunan skor daya ingat WAIS digitspan backward dan secara statistik signifikan. Penurunan skor post test kelompok perlakuan disebabkan oleh efek dari dehidrasi ringan hal ini sesuai dengan teori yang menyatakan bahwa kehilangan minimal 1\% cairan tubuh setelah perlakuan akan berpengaruh terhadap memori segera dan atensi. Pada saat aktivitas fisik, kebutuhan akan energi meningkat, sehingga kecepatan metabolisme meningkat. Hal ini mengakibatkan peningkatan suhu tubuh, dan kinerja saraf otonom simpatik pada hipotalamus anterior mengaktivasi kelenjar 
keringat ekrin. Kelenjar keringat akan menyerap air, $\mathrm{NaCl}$ dan sedikit urea dari kapiler darah, kemudian akan di keluarkan kepermukaan kulit melalui pori-pori (Guyton, 2012). Pada kelompok kontrol didapatkan uji WAIS digitspan backward yang mengalami peningkatan skor. Peningkatan skor pada uji WAIS digitspanbackward mungkin terjadi karena subjek telah mengerti mekanisme tes. Pada saat uji WAIS digitspan backward seringkali subjek harus dijelaskan lebih dari satu kali oleh penguji agar subjek faham, dan terkadang subjek baru mengerti mekanisme tes setelah trial test sehingga pada uji post test hasilnya lebih baik.

Hasil analisa Chi-Square pada tabel 1.3 menunjukan hasil yang signifikan, namun pada kelompok perlakuan masih terdapat subjek yang tidak mengalami mengalami penurunan fungsi daya ingat/atensi, hal ini mungkin terjadi karena selain dari faktor dehidrasi, kemampuan daya ingat pada kelompok perlakuan juga dipengaruhi oleh faktor lain yang tidak sepenuhnya bisa dikendalikan oleh peneliti, seperti ekspresi gen (CREP-C/EBP Pathway), neuromodulator (dopamin, adrenalin, stress hormon kortikosteroid, insulin growth factor II, perilaku) (Stern, 2014), paparan cahaya (Shan, et all. 2015) kualitas tidur (REM dan NREM) (Lau, et all. 2015), polusi udara (Gatto, 2015), kebiasaan bermain musik (Suarez, 2016), extensive cognitive learning (seperti mempelajari trik sulap, kebiasaan membaca, mempelajari warna, aktivitas motorik, video game, atau mediasi) (Koch, 2015) yang tidak sepenuhnya dapat kami singkirkan.

Untuk mengetahui korelasi antara antara beratnya dehidrasi dan penurunan memori segera/atensi dapat dilihat pada tabel Pada tabel 1.6 uji NP Nonparametric Correlations Spearman's didapat nilai $\mathrm{P}=0.004$ artinya ada korelasi antara beratnya dehidrasi dengan penurunan memori segera/atensi dan untuk melihat berapa kontribusi dehidrasi pada kejadian penurunan memori segera/atensi kita gunakan uji Regression (gambar 1.1), dari hasil uji regresi menunjukkan adanya korelasi antara beratnya dehidrasi dengan penurunan memori segera/atensi dan korelasinya negatif artinya semakin besar nilai dehidrasi maka semakin berat derajat penurunan memori segera/atensi. Kondisi seperti ini mendukung penelitian Harris R Lieberman, 2012 yang membuktikan bahwa dehidrasi memberikan pengaruh pada fungsi kognitif, peforma, dan mood (suasana hati), dangan uji Cognitive Performance and self report questionnaires. Penelitian Lawrence E. Armstrong, 2012, mengunakan sampel 25 orang perempuan dengan usia rata-rata 23 tahun di induksi dehidrasi dengan aktivitas fisik dan tablet diuretik, menunjukan adanya penurunan skor pada uji cognitive test battery (computerized cognitive test software, version 1.2.4). Hasil penelitian ini membuktikan bahwa dehidrasi dapat mempengaruhi fungsi fisiologis otak dan berpengaruh pada fungsi kognisi termasuk diantaranya fungsi memori segera/atensi 


\section{KESIMPULAN DAN SARAN}

\section{Kesimpulan}

1. Ada hubungan antara dehidrasi dengan penurunan memori segera/atensi

2. Prosentase penurunan memori segera/atensi pada kelompok tidak dehidrasi adalah $16,1 \%$

3. Prosentase penurunan memori segera/atensi pada kelompok dehidrasiadalah $30,6 \%$

4. Korelasi antara beratnya dehidrasi dengan penurunan memori segera/atensi adalah negatif artinya semakin besar nilai dehidrasi maka semakin berat derajat penurunan memori segera/Atensi.

\section{Saran}

1. Melakukan penelitian lanjutan untuk mengetahui memori segera/atensi pada mahasiswa laki-laki dan perempuan adakah perbedaannya, dan penelitian lanjutan apakah rehidrasi akan memperbaiki derajat memori segera/atensi.

2. Dilakukan penelitian ulang dengan melakukan pemelihan sampel yang ketat dengan melihat faktor-faktor lain yang mempengaruhi daya ingat seperti ekspresi gen (CREP-C/EBP Pathway), remodelling sinaps, neuromodulator (dopamin, adrenalin, stress hormon kortikosteroid, insulin growth factor II) perilaku, paparan cahaya, kualitas tidur

\section{DAFTAR PUSTAKA}

Alberini, Cristina M. And Eric R. Kendel. 2015. The regulation of Transcription in Memory Consolidation. Cold Spring Harbor Laboratory Press. Pp. 3-6

Armstrong, Lawrence E,et al., 2012. 'Mild Debydration Effects Mood in Healtby Young Women'. TheJournal of Nutrition Ingestive Behavior and Neurosciences. pp. 383-385

Bahrudin, Moch. 2011. Pemeriksaan Klinis di Bidang Penyakit Syaraf. Malang: UMM Press. Bab 4. Pemeriksaan status mental. Bab 4. Pemeriksaan status mental (neurobehavior/fungsi luhur).Pp. 31-33

Bahrudin, Moch. 2012. Neuroanatomi dan Aplikasi Klinis. Malang: UMM Press. Bab 1. Sistem saraf. Pp. 11-18, Bab 2. Susunan Saraf Pusat. Pp.33-38

Benton, David. 2011. Dehydration Influences Mood and Cognition. Journal Nutrients. pp. 559-565

Biller, A. Et al. 2015. Responses of the Human Brain to Mild Debydration and Rebydration Explored In Vivo by H-MR Imaging and Pectroscopy. AJNR AM J Neuroradiol 36:2277-84. Pp: 2279-2283

Esmaeilpour, Khadijeh, et all. 2015. Caffeine Improved Spatial Learning and Memory Deficit in Sleep Deprived Female Rat. Journal of Iranian Society if Physiology and Pharmacology. Pp:123127 
Ganio, Matthew S,et al., 2011. 'Mild Debidration Impairs Cognitive Performance and Mood of Men. British Journal of Nutrition. pp. 1536-1541

Gatto, Nicole M, et all. 2015. Components of Air Pollution and Cognitive Function in Middle Aged and Older Adults in Los Angeles. Neurotoxicology National Institude of Health 40: 1-7/ doi:10.1016 pg. 5-8

Ginsberg, Lionel. 2008. Lecture Notes: Neurologi Edisi kedelapan. Jakarta: Penerbit Erlangga. Bab 3. pp. $13-17$

Gustam. 2012. 'Faktor Risiko Dehidrasi pada Remaja dan Dewasa'. Jurnal institut Pertanian Bogor. pp. $27-66$

Guyton, Arthur C. 2012. Textbook of Medical Physiology. Philadelphia: Elsevier Inc. Unit V. Chapter 26. Urine formation by the kidney dan Unit IX. Chapter 46. Sesnsory receptor, neural circuit for processing information. pp. 307-604

Haro, Daniel Reyes. 2015. Dehydration-Induced Anorexia Reduces Astrocyte Density in the Rat Corpus Callosum. Neural Plasticity, Volume 2015, Article ID 474917. Pp: 4

Haryono, Andreas. 2011. Hubungan Karateristik Mahasiswa dangan Tingkat Gejala Anxietas pada Mahasiswa program Studi Pendidikan Dokter Universitas Tanjung Pura Angkatan 2006, 2007, 2008, dan 2009. Pp: 5-6

Hirano, Yukinori \& Minoru Saitoe. 2013. Hunger and memory; CRTC Coordinates Long-Term Memory with the Physiological State, Hunger. Communicative \& Integrative Biology Journal. ISSN: 1942-0889 journal homepage: http://www.tandfonline.com.loi/kcib20. pp: 2-3

http://www.human-memory.net/intro what.html (diakses tanggal 11 Juni 2015, pukul 13.00)

Johnson, Michael D. 2008. Human Biology Concept and Current Issues. San Francisco:Pearson Education Inc.

Johnson, Joyce Young. 2008. Fluids and Electrolytes Demystified. USA: The McGraw-Hill Companies Inc. Chapter 4 dan Chapter 5. pp. 61-87

Koch, Kathrin, Tim Jonas Rees, Oana Georgina Rus and Claus Zimmer. 2015. Extensive Learning is Associated with Gray Matter Changes in the Right Hippocampus. NeuroImage Journal, Elsevier Inc. DOI:10.1016. Pp. 2-5

Kogler, Lydia, et all. 2016. Sex Differences in the Fumctional Connectivity of the Amygdake in Association with Cortisol. Neuroimage 134 (2016) 410-423. Pp: 413-420 
Kong, Dong, John N Campbell, Bernardo L Sabatini, Bradford B Lowell. 2016. A Postsynaptic AMPK p21-Activated Kinase Pathway Drives Fasting-Induced Synaptic Plasticity in AgRP Neurons. Elsevier. Inc. pp:3-6

Kumar, Navneet, et all. 2016. Efficacy of Standarizes Extract of Bacopa monnieri (Bacognize) on Cognitive Function of Medical students: A six-week, Randomized Placebo-Controll Trial. Hindawi Publishing Corporation Evidence-Based Complementary and Alternative medicine. ID 4103423. Pp. $2-5$

Lau, Esther Yuet Ying Lau,et all. 2015. Rapid-Eye-Movement-Sleep (REM) Associated Enhancement of Working Memory Performance after a Daytime Nap. Journal Pone 0125752 University of Hongkong. Pg.3-12

Lieberman, Harris R. 2012. Methods for Assesing the Effects of Debydration on Cognitive Function. Suplement Article Nutrition Reviews. pp. 143-145

Moralez, Gilbert,et al.2012. Effects of Debidration on Cerebrovascular Control During Standing After Heavy Resistance Exercise. J Appl Physiol. pp. 1875-1881

Najafabadi, Mahboubeh Ghayour, et al. 2015. Does Ramadan fasting Adversely AffectCognitive Function in Young Females?. Hindawi Publishing Corporation Scientifica. Volume 2015, Article ID 432428. pp: $2-4$

Pearce, Evelyn C. 2009. Anatomi Fisiologi untuk Paramedis. Jakarta: PT Gramedia Pustaka Utama. Bab 1 dan Bab22. 6-340

Pedro, Consuelo M A. 2015. Relationship Between Physiological and Clinical Measure of Prospective Memory in Individuals with Mild Acquired Brain Injury, Severe Acquired Brain Injury and Healtby Adult. Thesis of Neuroscience Program Hartford, Connecticut. Pp: 47-57

Pego, C. Ferreira, et all. 2015. Total Fluid Intake and Its Determinants: Cross-sectional Surveys Among Adult in 13 Countries Worlwide. Europe Journal of Nutrition 54

Penggalih, Mirza Harapan Sakti titis. 2013. Prevalensi Kasus Dehidrasi Pada Mahasiswa Universitas Gadjah Mada. Pp. 3-10

Prasetya, Ari, Gana Adyaksa, Yosef Purwoko. 2015. "Pengaruh Pemberian Minuman Isotonik terhadap Memori pada Keadaan Dehidrasi (Studi Banding dengan Air mineral). Jurnal Universitas Diponegoro Volume 4 Nomor 4. Pp: 411-415

Putriana, Dittasari, 2014, Konsumsi Cairan Periode Latihan dan Status Hidrasi Setelah Latihan pada Atlet Sepak Bola Remaja. Fakultas Kedokteran Universitas Diponegoro Semarang.

Roca, Miquel, et all. 2015. Cognitive Impairments and Depression. Pp: 188-192 
Saladin, Kenneth S.2010.Anatomy \&Physiology. The unity of Form and Function 5th ed.New York:McGraw-Hill. (Pg. 943-947)

Shan Li-Li, et all, 2015. Light Exposure Before Learning Improves Memory Consolidation at Night. Scientific Report 5:15578. Pg. 3-8

Sitohang, Nur Asnah, dan Farida Linda Sari Siregar. 2015. Effect of Nutrition Therapy Dates for Short Term Memory of Students at Elementary School 060886 and 060 889. Journal of Nursing and Health Care (JNHC) Vol.2 No.2. Pp:87-89

Spiers, Mary V. Eric A Zillmer. 2008.Principles of Neuropsychology second edition. USA: Thomson Higher Education. Chapter 9. pp. 225-240

Stern, Sarah A, dan Cristina M Alberini. 2014. Mechanisms of Memory Enhancement. National Institude of Health

Streitburger, Daniel Paolo, et al. 2012. Investigating Structural Brain Changes of Debydration Using VoxelBsed Morphometry. Volume 7, Issue 8. Pp. 7

Suarez, Lidia. Shalini Elangovan, dan Agnes Au. 2016. Cross-sectional Study on the Relationship Between Music Training and Working Memory in Adult. Australian Journal of Psychology. DOI: 10.111/ajpy.12087. pp. 40-42

Syaifuddin. 2009. Fisiologi Tubuh Manusia. Jakarta: Penerbit Salemba Medika

Talumewo, Veyna Reysa. Et All. 2014. Stress terhadap Daya Tahan Belajar pada mahasiswa Angkatan 2013 Fakultas Kedokteran Universitas Sam Ratulangi. Pp: 4

Trangmar, Steven J. Et al. 2015. Debydration Accelerates Reduction in Cerebral Blood Flow During Prolonged Exercise in the Heat Withpout Compromising Brain Metabolism.American Physiological Society. ISSN 0363-6135. Pp: H1600-H1603

Tantomi, Achmad Iwan, et al., 2013.'Tren Fenomena 'PisiDi' (Pikun Usia Dini) Sebagai Dugaan Awal Gejala Demensia. Jurnal Universitas Islam Malang. pp. 2-4

Tiwari, Ram Kalap. 2015. Benefits of Yoga Practices in High School Student's Memory and Concentration in Relation to Examination Stress. International Journal of Yoga and Allied Science. Volume 4, issue 2. Pp: $79-81$

Warden, Clara, Et all. 2016. The Effect of Dopamine on Digit Span in Parkinson's Disease. Journal of Clinical Movement Disorder. DOI: 10.1186/s40734-016-0033-z. pp.2-8

Zulkarnain.2014. Peran Latihan Fisik teratur terhadap Fungsi Memori dan Kognitif Wanita Pascamenopause. Pp: 168-171 